\title{
Genetic cholestasis: Lessons from the molecular physiology of bile formation
}

Peter LM Jansen MD, Michael Müller PhD

PLM Jansen, M Müller. Genetic cholestasis: Lessons from the molecular physiology of bile formation. Can J Gastroenterol 2000;14(3):233-238. Progressive familial intrahepatic cholestasis (PFIC) is a group of severe genetic cholestatic liver diseases of early life. PFIC types 1 and 2 are characterized by cholestasis and a low to normal serum gamma-glutamyltransferase (GGT) activity, whereas in PFIC type 3, the serum GGT activity is elevated. PFIC types 1 and 2 occur due to mutations in loci at chromosome 18 and chromosome 2 , respectively. The pathophysiology of PFIC type 1 is not well understood. PFIC types 2 and 3 are caused by transport defects in the liver affecting the hepatobiliary secretion of bile acids and phospholipids, respectively. Benign recurrent intrahepatic cholestasis (BRIC) is linked to a mutation in the same familial intrahepatic cholestasis 1 locus at chromosome 18. Defects of bile acid synthesis may be difficult to differentiate from these transport defects.

Intrahepatic cholestasis of pregnancy (ICP) appears to be related to these cholestatic diseases. For example, heterozygosity in families with PFIC type 3 is associated with ICP, but ICP has also been reported in families with BRIC.

In Dubin-Johnson syndrome there is no cholestasis; only the hepatobiliary transport of conjugated bilirubin is affected. This, therefore, is a mild disease, and patients have a normal lifespan.

Key Words: Bile; Bile salt export pump; Cholestasis; Dubin-Johnson syndrome; P-glycoprotein; Progressive familial intrahepatic cholestasis
Cholostase génétique : Les leçons de la physiologie moléculaire de la formation biliaire

RÉSUMÉ : La cholostase intra-hépatique familiale progressive (CIFP) regroupe des maladies hépatiques cholostatiques génétiques graves survenant tôt au cours de la vie. Les CIFP de types I et II se caractérisent par une cholostase et une activité de faible à normale de la gamma-glutamyltransférase (GGT) sérique, alors que la CIFP de type III s'accompagne d'une activité accrue de la GGT sérique. La CIFP de types I et II survient suite à des mutations des loci situés dans les chromosomes 18 et 2, respectivement. La physiopathologie de la CIFP de type I est encore mal élucidée. La CIFP de types II et III est causée par une anomalie du transport hépatique affectant la sécrétion hépatobiliaire des acides biliaires et des phospholipides respectivement. La cholostase intra-hépatique récurrente bénigne (CIRB) est liée à une mutation du même locus FIC-1 sur le chromosome 18. Les anomalies de synthèse de l'acide biliaire peuvent être difficiles à distinguer de ces anomalies de transport.

La cholostase intrahépatique associée à la grossesse (CIHP) semble liée à ces maladies cholostatiques. Par exemple, l'hétérozygotie notée dans les familles où sévit la CIFP de type III est associée à la CIHP, mais la CIHP a aussi été observée dans les famille touchées par la CIRB.

Dans le syndrome de Dubin-Johnson, il n'y a pas de cholostase, seul le transport hépatobiliaire de la bilirubine conjuguée est affecté. Il s'agit donc d'une maladie bénigne et les patients ont une espérance de vie normale.
$\mathrm{T}$ he secretion of solutes in bile depends on the activity of transporter proteins in the sinusoidal and canalicular membranes of hepatocytes. Bile acids, bilirubin and various other endogenous metabolites are delivered to the liver via the portal blood. Sinusoidal membranes of the hepatocytes contain carrier proteins that are capable of extracting plasma protein-bound compounds, which are taken up by the liver.
In the liver, many of these metabolites are further metabolized in preparation for biliary secretion. For example, unconjugated bilirubin cannot be secreted as such into bile, but after conjugation with glucuronic acid, bilirubin becomes a substrate for transporter proteins in the canalicular membrane of the hepatocyte.

Bile formation starts with the active transport of solutes

This mini-review was prepared from a presentation made at the World Congress of Gastroenterology, September 6 to 11, 1998, Vienna, Austria Division of Hepatology and Gastroenterology, University Hospital Groningen, The Netherlands

Correspondence and reprints: Prof dr Peter LM Jansen, Division of Hepatology and Gastroenterology, University Hospital Groningen

Hanzeplein 1, 9713 GZ Groningen, The Netherlands. Telephone+31 50 3612620,fax+3150 3619306,e-mail P.L.M.Jansen@int.azg.nl

Received for publication June 28, 1999. Accepted July 5, 1999 


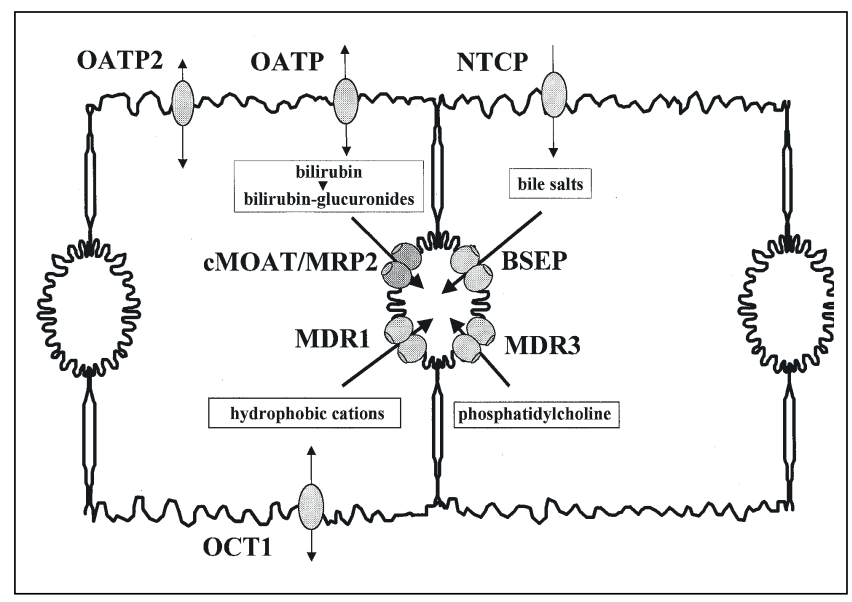

Figure 1) Hepatic transport pumps. Two hepatocytes are shown with three canaliculi. Each canaliculus is surrounded by specialized membrane domains of the hepatocyte and is sealed off by tight junctions. The specialized membrane domains contain the ATP-dependent transporters, canalicular multispecific organic anion transporter/multidrug resistant-associated protein 2, bile salt export pump (BSEP), MDR1 and MDR3 pumping organic anions, bile salts, hydrophobic cations and phosphatidylcholine from liver to bile. The sinusoidal membrane contains transporters for the uptake of organic anions (organic anion transporter protein [OATP]), bile salts (sodium-dependent taurocholate cotransporter protein [NTCP]) and organic cations (organic cation transporter 1 [OCT1])

from hepatocytes across the plasma membrane into the bile canaliculus. For this active secretion, the hepatocyte is equipped with a number of transmembrane transporter proteins. These proteins are able to pump solutes against a steep concentration gradient into bile. Many of these transporters have been cloned. This review concentrates on genetic cholestasis. This interest is motivated by the fact that genetic cholestatic liver diseases are experiments of nature that prove the importance of hepatic transport and hepatic transporter proteins.

\section{MOLECULAR PHYSIOLOGY}

For the hepatic uptake of bile salts, organic anions and cations, the basolateral membrane of the hepatocyte contains a sodium-dependent taurocholate cotransporter protein (NTCP), organic anion transporters (OATP in humans and oatpl and oatp2 in rodents) and an organic cation transporter (OCT1) (1-3) (Figure 1). These transporters are not directly ATP-dependent for their function. They function as facilitators for the diffusion of a broad but specified group of substrates. In the circulation, many cholephilic compounds are firmly bound to plasma proteins. The plasma membrane transporters may play a role in the hepatic extraction of these compounds. As yet, no genetic diseases have been identified in which these proteins are involved. Among patients with unconjugated hyperbilirubinemia, there may be a subgroup with an uptake defect for unconjugated bilirubin $(4,5)$. This has not been studied at the molecular level.

Transporters, mediating the secretion from liver to bile, belong to the family of ATP-binding cassette proteins. This family, of which about 500 members are cloned, is ubiquitous in nature and is found in prokaryotes, nematodes, insects, plants and mammals. In humans, members of this transporter protein family include the P-glycoproteins (MDRs), the multidrug resistance proteins (MRPs), the cystic fibrosis transmembrane regulator, the transporter associated with antigen presentation (TAP) proteins and a peroxisomal long chain fatty acid transporter. In the liver, the canalicular membrane is particularly rich in $\mathrm{ABC}$ transporters; the most important components are the bile salt export pump (BSEP) (also called sister of P-glycoprotein), the canalicular multispecific organic anion transporter (cMOAT or MRP2), a canalicular phosphatidylcholine translocator (MDR3) and the MDR1 P-glycoprotein, a transporter for drugs and other hydrophobic compounds (2). In cancer cells, the overexpressed MDR1 P-glycoprotein is actively engaged in the extrusion of drugs and thus contributes to their MDR phenotype.

Bile salts, phospholipids, cholesterol and glutathione are the dominant solutes of bile. Bile salts in bile participate in the enterohepatic circulation. This mechanism, which can be described as a series of bile salt pumps, is aimed at the conservation of bile salts. The ATP-dependent canalicular BSEP of the periportal hepatocytes has a dominant role in the enterohepatic circulation of bile salts. Bile salts enter the liver via the portal blood and are taken up and secreted by the hepatocytes of acinar zone I, the periportal hepatocytes.

Hepatocytes of zone III, the centrilobular hepatocytes, mainly secrete newly formed bile salts. NTCP and the ileum bile salt transporter (IBST) also play a role in the enterohepatic circulation of bile salts. NTCP is the protein responsible for hepatic uptake of bile salts. IBST is the main intestinal bile salt transporter - the only intestinal bile salt transporter cloned thus far. Mutations in the $i B S T$ gene lead to persistent bile salt diarrhea $(6,7)$. Mutations of the NTCP gene have not been identified.

The movement of phosphatidylcholine through the canalicular membrane is catalyzed by MDR3, which, like BSEP, is an ATP-dependent P-glycoprotein. In rodents, MDR3 is called mdr2. The secretion of cholesterol follows that of phosphatidylcholine and bile salts. An mdr2 $2^{-l}$ (knockout) mouse cannot secrete phosphatidylcholine, and as a consequence there is hardly any biliary cholesterol secretion (8). This does not necessarily mean that mdr2/MDR3 is also a cholesterol carrier but that phospholipid secretion is a minimal requirement for cholesterol secretion. Other components of the phospholipid and cholesterol secretory pathways include the intracellular binding proteins, phosphatidylcholine transfer protein and sterol-carrier protein 2 .

Hepatobiliary transport of glutathione, the glucuronideconjugates of bilirubin, the glutathione-, glucuronide- and sulphate-conjugates of drugs, and many other compounds, is mediated by cMOAT, which is also called MRP2 (9-11).

\section{PROGRESSIVE FAMILIAL INTRAHEPATIC CHOLESTASIS TYPE 1}

Progressive familial intrahepatic cholestasis (PFIC) is a group of diseases characterized by congenital cholestasis (Table 1). Byler disease, a well known member of this group, 
TABLE 1

Characteristics of progressive familial intrahepatic cholestasis (PFIC)

\begin{tabular}{lcccc}
\hline Disease & Chromosome & Defect & Pathology & Symptoms \\
\hline PFIC type 1 & $18 q 21-q 22$ & P-type-ATPase & Bland cholestasis & $\begin{array}{c}\text { Cholestasis, stunted growth, } \\
\text { diarrhea, pancreas insufficiency }\end{array}$ \\
PFIC type 2 & $2 q 24$ & Canalicular bile salt export & $\begin{array}{c}\text { Frequently starts as neonatal } \\
\text { hepatitis, later bland cholestasis }\end{array}$ & $\begin{array}{c}\text { Neonatal hepatitis, cholestasis, } \\
\text { stunted growth }\end{array}$ \\
PFIC type 3 & $7 q 21$ & $\begin{array}{c}\text { Canalicular phosphatidylcholine } \\
\text { translocator-MDR3 }\end{array}$ & $\begin{array}{c}\text { Impressive bile duct proliferation } \\
\text { Pruritis, cholestasis }\end{array}$ \\
Dubin-Johnson syndrome & $10 q 24$ & CMOAT/MRP2 & $\begin{array}{c}\text { Black hepatic pigment in } \\
\text { otherwise normal liver }\end{array}$ & Mild hyperbilirubinemia \\
\hline
\end{tabular}

CMOAT Canalicular multispecific organic anion transporter; MRP Multidrug resistance-associated protein

is also called PFIC type 1. Byler disease was founded by Jacob Byler, a farmer of Amish ancestry who settled in Pennsylvania in the late 18th century. Patients initially have recurrent cholestasis, but cholestasis very soon becomes persistent (12). Bile of these children is deficient in bile acids and particularly devoid of chenodeoxycholic acid. The liver biopsy shows bland cholestasis without much bile duct proliferation. Clinically, the disease is characterized by jaundice, diarrhea, decreased growth and a relatively low to normal serum gamma-glutamyltransferase (GGT) activity, elevated serum bile acid levels and an elevated alkaline phosphatase level. Positional cloning studies in a large Byler kindred revealed a mutation in a locus at chromosome $18 \mathrm{q} 21$-q22, the FIC-1 locus (13-15). Bull et al (16) suggested that this mutation affects a member of the family of P-type ATPases (16). This family is comprised of P1-ATPases, which mediate metal transport including copper, and P2-ATPases for the transport of cations such as hydrogen/potassium-ATPase in the gastric mucosa. The P-ATPase involved in PFIC type 1 appears to have homology to a putative ATP-dependent aminophospholipid transporter. This transporter may act as a flippase, moving phosphatidylserine and phosphatidylethanolamine from the outer membrane leaflet to the inner leaflet, thus establishing an assymetric distribution of phospholipids in the plasma membrane. This organization may be needed either for the function of transmembrane transporters or for the membrane insertion of newly synthesized transporter proteins. However, the P-ATPase that is putatively implicated in PFIC-1 is not expressed in hepatocytes but seems more important in cholangiocytes, the intestine and the pancreas (16). Although this explains the extrahepatic manifestations such as pancreas insufficiency, sweat electrolyte abnormalities and intestinal malabsorption, it is difficult to equate with cholestasis as the most prominent symptom. The pathophysiology of PFIC type 1 would be more compatible with hepatic dysregulation of bile salt secretion or with intestinal bile salt malabsorption with, as a consequence, formation of toxic monohydroxy bile salts in the colon. This argument is supported by the fact that benign recurrent intrahepatic cholestasis (BRIC), characterized by recurrent bouts of cholestasis and intervals of entirely normal liver function, is genetically related to Byler disease (17). Both
BRIC and PFIC type 1 are associated with mutations in the FIC-1 gene (15-18). However, neither all patients with a PFIC-phenotype, nor all patients with BRIC, have a mutation at the chromosome 18 FIC-1 locus (14-19).

\section{PFIC TYPE 2}

PFIC type 2 is characterized by persistent neonatal cholestasis. It often presents as neonatal hepatitis. As with PFIC type 1 , the liver histology of patients with PFIC type 2 does not show much bile duct proliferation, and the general picture is one of bland cholestasis. As in PFIC type 1, serum bile acids and alkaline phosphatase activity are elevated and GGT activity is normal. Strautnieks et al $(20,21)$ mapped the gene defect for this disease to a locus at chromosome $2 \mathrm{q} 24$, the FIC-2 locus $(20,21)$. This disease appears to result from a defect of hepatobiliary bile salt transport.

Bile salts are secreted into bile against a very steep concentration gradient. Therefore, it is not surprising that bile salt secretion is an ATP-dependent process. This was known many years before the implicated transporter was cloned. Concentrative bile salt transport seems to be a specific liver function. For example, ileal bile salt transport is not concentrative but downhill from the bile salt-rich intestinal lumen to the blood. Recently, a candidate protein for the canalicular bile salt transport has been cloned $(22,23)$. It belongs to the MDR/TAP subfamily of ABC-transporter proteins and is called the BSEP. In humans, this protein is encoded by a gene on chromosome 2q24, the locus to which PFIC type 2 has been mapped. The mutations of the BSEP gene identified thus far are shown in Table 2. Strautnieks et al (20) found single nucleotide substitutions (nonsense and missense mutations), deletions and insertions. Figure 2 shows sites in the BSEP protein that are predicted to be affected by mutations.

\section{PFIC TYPE 3}

Deleuze et al (24) and de Vree et al (25) characterized a third type of PFIC, PFIC type 3. In contrast with patients with PFIC type 1, BRIC and PFIC type 2, patients with PFIC type 3 have a high serum GGT activity. This disease is characterized by pruritus followed by jaundice and cirrhosis. Patients with PFIC type 3 produce bile salt-containing bile without 
TABLE 2

Mutations in the bile salt export pump gene (BSEP)

\begin{tabular}{ccc}
\hline Codon & Nucleotide & Amino acid \\
\hline Nucleotide substitutions (missense and nonsense mutations) \\
$297^{*}$ & GAG-GGG & Glu-Gly \\
461 & aAAA-GAA & Lys-Glu \\
482 & GAT-GGT & Asp-Gly \\
$575^{+}$ & cCGA-TGA & Arg-Term \\
982 & CGGA-AGA & Gly-Arg \\
1057 & cCGA-TGA & Arg-Term \\
1153 & cCGC-TGC & Arg-Cys \\
1268 & CGG-CAG & Arg-Cln
\end{tabular}

Small deletion

302

AGGT $^{\wedge}$ TGAAAGgTATG

AGAAAA

Small insertion

$3767^{\ddagger}$

$1256 \mathrm{C}$

* Strautnieks et al (14) found homozygous missense mutations in seven families with progressive familial intrahepatic cholestasis (PFIC) type 2: an adenine (A) to guanine (G) transition at nucleotide 890 led to a glutathione (Glu) 297 to glycine (Gly) substitution in the intracellular loop between transmembrane spans 4 and 5. Heterozygous missense mutations were found in 6 families; ${ }^{\dagger}$ In addition, cytosine (C) to thymine (T) transitions at nucleotide 1723, resulting in an arginine (Arg) 575 to terminal (Term) substitution, were found with premature truncation of the BSEP protein. A Latin American family carried the same mutation in homozygous form; in the Belgian family, the mutation was heterozygous and the mutation on the other allele was not identified; ${ }^{\ddagger}$ In one family, the PFIC2 phenotype was associated with homozygosity for insertion of one nucleotide, a C, between nucleotides 3767 and 3768. This resulted in a change in amino acid 1256, with the introduction of 39 novel amino acids followed by truncation of the protein (21). Asp Aspartate; Cys Cysteine; Gln Glutamine; Lys Lysine

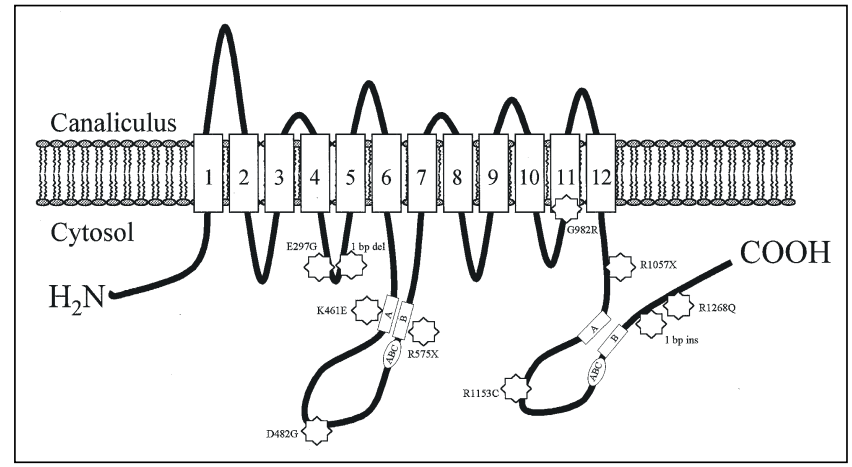

Figure 2) Mutations in the bile salt export pump (BSEP). The structure of BSEP in the canalicular membrane is shown with indications of the various mutations reported by Strautnieks et al (21). BSEP is proposed to have 12 membrane-spanning domains. $A B C$ 'signatures' $(A B C)$ and Walker $A$ and $B(A$ and $B)$ motifs together form the nucleotide-binding folds, which are present in duplicate. bp del Base pair deletion; bp ins Base pair insertion

phospholipids. The histological abnormalities of these patients and those of the $\mathrm{mdr} 2^{-1-}$ knockout mice are remarkably similar. They consist of periportal inflammation, extensive bile duct proliferation, feathery degeneration of hepatocytes, fibrosis and, in the knockout mice, malignancy
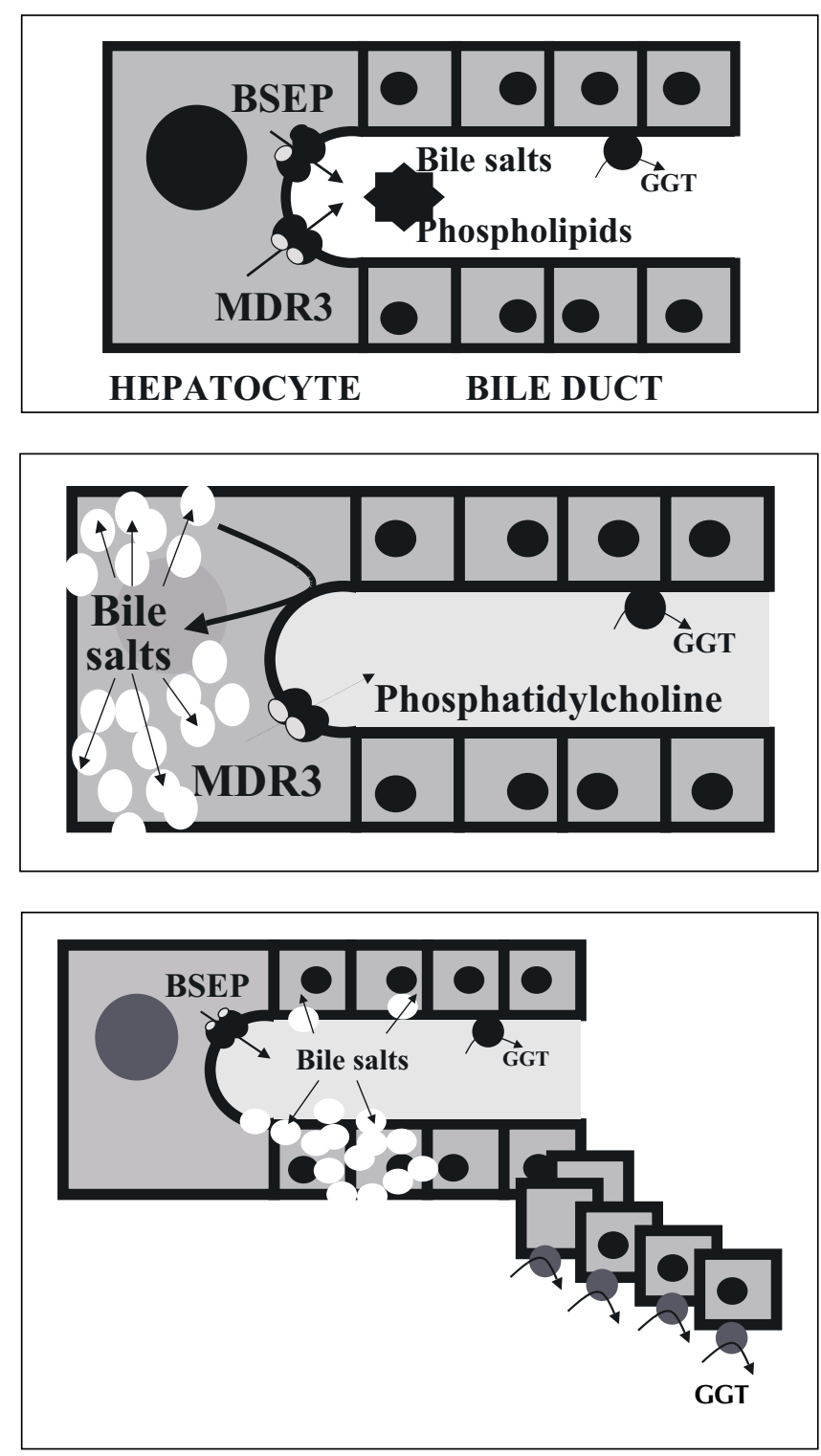

Figure 3) Progressive familial intrahepatic cholestasis (PFIC) disease mechanisms. Top MDR3 is a flippase, translocating phosphatidylcholine (PC) from the cytosolic leaflet of the canalicular membrane to the leaflet facing the bile duct lumen. Bile salts are pumped into the canaliculus by the bile salt export pump (BSEP). Bile salts remove PC from the canalicular membrane to form mixed micelles containing bile salts, PC and cholesterol. Middle In PFIC type 2, BSEP is not expressed. Therefore PC secretion is very low (faint arrow). Bile salts accumulate in the hepatocyte, cause damage and induce apoptosis. Bile, devoid of bile salts, cannot release gamma-glutamyltransferase (GGT) from the bile ducts. Therefore the serum GGT activity in these patients is low, despite the cholestasis. Bottom In PFIC type 3, MDR3 is not expressed. Therefore bile salts are pumped into the canaliculus unaccompanied by PC. Bile without PC is toxic to the bile ducts (bile salts are membranolytic). Damaged bile ducts proliferate and with the help of bile salts they shed large amounts of GGT into the circulation

of the liver. The hypothesis is that this histological picture is due to the cytotoxicity of bile salts, which in normal bile is antagonized by phospholipids.

Two patients described by de Vree et al (25) lacked MDR3 in the liver. Reverse transcriptase polymerase chain 
reaction revealed homozygous mutations in the MDR3 mRNA. Genomic DNA analysis of their parents showed that they are heterozygous for this mutation. A nondiseased sister of one of the patients is homozygous normal. None of the two described patients responded to ursodeoxycholic acid (UDCA) therapy. The authors speculated that patients with the complete MDR3 defect do not respond to UDCA, whereas responding patients (about $50 \%$ in this disease) have a partial defect $(25,26)$. Figure 3 shows the so called 'secretory unit' of the liver with the defects in the various PFIC subtypes.

\section{INTRAHEPATIC CHOLESTASIS OF PREGNANCY}

Intrahepatic cholestasis of pregnancy (ICP) is characterized by jaundice, pruritus, a moderate increase in serum bile acids, a mild elevation of serum transaminases and elevated conjugated bilirubin levels. ICP occurs in late pregnancy and disappears after delivery. Women with ICP may have had a period of pruritus or mild cholestasis during the use of estrogen-containing contraceptives. ICP usually reappears during subsequent pregnancies. Stillbirth or premature births are feared complications. UDCA therapy has a beneficial effect on the disease in the mother and on the outcome of pregnancy (27-29). The etiology of ICP is unknown. ICP has been reported to occur in families with BRIC (30) and in families with PFIC type 3 (31).

\section{DUBIN-JOHNSON SYNDROME}

The transport mutant rat provides an animal model for Dubin-Johnson syndrome. In these rats, the biliary secretion of conjugated bilirubin, glutathione, glutathione S-conjugates, 3-O-glucuronidated and sulphated bile salts is severely depressed $(32,33)$. When placed on a tryptophancontaining diet, these rats develop the characteristic black liver pigment seen in patients with Dubin-Johnson disease (34). Recently, the molecular defect in these rats has been elucidated and appears to be a mutation of the c-moat gene $(35,36)$. Patients with Dubin-Johnson syndrome have a mild conjugated hyperbilirubinemia, a black pigment in the liver, a characteristic bromosulphthalein disappearance curve (with a secondary rise) and an elevated urinary excretion of coproporphyrin isomer I. It is a mild disease, and patients with Dubin-Johnson syndrome have a normal life span. $\mathrm{Mu}$ tations in the cMOAT/MRP2 gene form the basis of the defective cMOAT/MRP2 expression in the canalicular membranes in these patients (37-39). During pregnancy, patients with Dubin-Johnson syndrome may become deeply jaundiced; however, this is caused by a rise in serum bilirubin, and serum bile salt levels remain normal and signs of cholestasis such as pruritus do not occur (40). This provides evidence against the argument that estrogen metabolites, which are increased during pregnancy and are secreted into bile via cMOAT/MRP2, are major factors in the etiology of ICP. If that were so, patients with Dubin-Johnson syndrome would be prone to developing ICP, which is not the case.

\section{OTHER GENETIC CHOLESTATIC DISEASES}

At least 17 different enzymes are involved in the synthesis of bile acids. Mutations in some of these enzymes have been described as the underlying cause of cholestatic diseases with variable expression. As with PFIC types 1 and 2, patients with 3-beta-hydroxy- $\mathrm{C}_{27}$-steroid dehydrogenase/isomerase deficiency have normal serum GGT-activity, elevated conjugated bilirubin levels, increased transaminase activity and normal serum bile acid levels. It may seem surprising that these patients have normal serum bile acid levels, but this occurs because routine assays do not detect the abnormal bile acids formed in these patients $(41,42)$. Other defects include those resulting from deficiencies of delta ${ }^{4}-3$ oxosteroid-5-beta-reductase and some other enzymes of the bile acid synthetic pathway. Interestingly, some of the bile acid intermediate metabolites are severely cholestatic in that they inhibit the secretion of normal bile acids (43). Recently, Arnon et al (44) reported a cholesterol 7-alphahydroxylase knockout mouse with neonatal cholestasis caused by toxic monohydroxy bile acids that are synthesized via the undisturbed cholesterol 27-hydroxylase pathway. Mutation of this gene in humans is a cause of severe neonatal liver disease (45).

\section{CONCLUSIONS}

Will the patients with genetic cholestasis or their families benefit from these new insights in bile salt metabolism? Although not practised yet, prenatal diagnosis in families with an affected child is possible. As for gene therapy, it may seem too early to speculate, but it is reasonable that the PFIC subtypes may be amenable to gene therapy if the gene can be administered before the liver becomes cirrhotic. Finally, hepatocyte transplantation has been shown to be a viable option in mdr2 $2^{-l-}$ knockout mice (46). Their human counterparts, patients with PFIC type 3, may be candidates for this elegant potential new therapy.

\section{REFERENCES}

1. Meier PJ, Eckhardt U, Schroeder A, Hagenbuch B, Stieger B. Substrate specificity of sinusoidal bile acid and organic anion uptake systems in rat and human liver. Hepatology 1997;26:1667-77.

2. Müller M, Jansen PLM. Molecular aspects of hepatobiliary transport. Am J Physiol 1997;272:G1285-303.

3. Hagenbuch B. Molecular properties of hepatic uptake systems for bile acids and organic anions. J Membr Biol 1997;160:1-8.

4. Berk PD, Blaschke TF, Waggoner JC. Defective bromosulphthalein clearance in patients with constitutional hepatic dysfunction (Gilbert's syndrome). Gastroenterology 1972;63:472-81.

5. Nambu M, Namihisa T. Hepatic transport of serum bilirubin, bromsulfophthalein, and indocyanine green in patients with congenital non-hemolytic hyperbilirubinemia and patients with constitutional indocyanine green excretory defect. J Gastroenterol 1996;31:228-36.

6. Craddock AL, Love MW, Daniel RW, et al. Expression and transport properties of the human ileal and renal sodium-dependent bile acid transporter. Am J Physiol 1998;274:G157-69.

7. Oelkers P, Kirby LC, Heubi JE, Dawson PA. Primary bile acid malabsorption caused by mutations in the ileal sodium-dependent bile acid transporter gene (SLC10A2). J Clin Invest 1997;99:1880-7.

8. Elferink RP, Tytgat GN, Groen AK. Hepatic canalicular membrane 1: The role of mdr2 P-glycoprotein in hepatobiliary lipid transport. FASEB J 1997;11:19-28.

9. Keppler D, Leier I, Jedlitschky G. Transport of glutathione conjugates 
and glucuronides by the multidrug resistance proteins MRP I and MRP2. Biol Chem 1997;378:787-91.

10. Keppler D, König J. Hepatic canalicular membrane 5: Expression and localization of the conjugate export pump encoded by the MRP2 (cMRP/cMOAT) gene in liver. FASEB J 1997;11:509-16.

11. Jedlitschky G, Leier I, Buchholz U, Hummel EJ, Burchell B, Keppler D. ATP-dependent transport of bilirubin glucuronides by the multidrug resistance protein MPR1 and its hepatocyte canalicular isoform MRP2. Biochem J 1997;327:305-10.

12. Clayton RJ, Iber FL, Ruebner BH, McKusick VA. Byler disease. Fatal familial intrahepatic cholestasis in an Amish kindred. Am J Dis Child 1969;117:112-24.

13. Bull LN, Carlton VE, Stricker NL, et al. Genetic and morphological findings in progressive familial intrahepatic cholestasis (Byler disease [PFIC-1] and Byler syndrome): evidence for heterogeneity. Hepatology 1997;26:155-64.

14. Strautnieks SS, Kagalwalla AF, Tanner MS, Gardiner RM, Thompson RJ. Locus heterogeneity in progressive familial intrahepatic cholestasis. J Med Genet 1996;33:833-6.

15. Carlton VE, Knisely AS, Freimer NB. Mapping of a locus for progressive familial intrahepatic cholestasis (Byler disease) to 18q21-q22, the benign recurrent intrahepatic cholestasis region. Hum Mol Genet 1995;4:1049-53.

16. Bull LN, van Eijk MJT, Pawlikowska L, et al. A gene encoding a P-type ATPase mutated in two forms of hereditary cholestasis. Nat Genet 1998;18:219-24.

17. Houwen RHJ, Baharloo S, Blankenship K, et al. Genome screening by searching for shared segments: mapping a gene for benign recurrent intrahepatic cholestasis. Nat Genet 1994;8:380-6.

18. Sinke RJ, Carlton VEH, Juijn JA, et al. Benign recurrent intrahepatic cholestasis (BRIC): evidence of genetic heterogeneity and delimitation of the BRIC locus to a 7-cM interval between D18S69 and D18S64. Hum Genet 1997;100:382-7.

19. Arnell H, Nemeth A, Anneren G, Dahl N. Progressive familial intrahepatic cholestasis (PFIC): evidence for genetic heterogeneity by exclusion of linkage to chromosome 18q21-q22. Hum Genet 1997;100:378-81.

20. Strautnieks SS, Bull LN, Knisely AS, et al. A gene encoding a liver-specific $A B C$ transporter is mutated in progressive familial intrahepatic cholestasis. Nat Genet 1998;20:233-8.

21. Strautnieks SS, Kagalwalla AF, Tanner MS, et al. Identification of a locus for progressive familial intrahepatic cholestasis PFIC2 on chromosome 2q24. Am J Hum Genet 1997;61:630-3.

22. Childs S, Yeh RL, Georges E, Ling V. Identification of a sister gene to P-glycoprotein. Cancer Res 1995;55:2029-34.

23. Gerloff T, Stieger B, Hagenbuch B, et al. The sister of P-glycoprotein represents the canalicular bile salt export pump of mammalian liver. J Biol Chem 1998;273:10046-50.

24. Deleuze JF, Jacquemin E, Dubuisson C, et al. Defect of mutildrug-resistance 3 gene expression in a subtype of progressive familial intrahepatic cholestasis. Hepatology 1996;23:904-8.

25. de Vree JM, Jacquemin E, Sturm E, et al. Mutations in the MDR3 gene cause progressive familial intrahepatic cholestasis. Proc Natl Acad Sci USA 1998;95:282-7.

26. Jacquemin E, Hermans D, Myara A, et al. Ursodeoxycholic acid therapy in pediatric patients with progressive familial intrahepatic cholestasis. Hepatology 1997;25:519-23.

27. Serrano MA, Brites D, Larena MG, et al. Beneficial effect of ursodeoxycholic acid on alterations induced by cholestasis of pregnancy in bile acid transport across the human placenta. J Hepatol 1998;28:829-39.

28. Paima J, Reyes H, Ribalta J, et al. Ursodeoxycholic acid in the treatment of cholestasis of pregnancy: a randomized, double-blind study controlled with placebo. J Hepatol 1997;27:1022-8.

29. Meng LJ, Reyes H, Axelson M, et al. Progesterone metabolites and bile acids in serum of patients with intrahepatic cholestasis of pregnancy: effect of ursodeoxycholic acid therapy. Hepatology 1997;26:1573-9.

30. de Pagter AGF, van Berge Henegouwen GP, ten Bokkel Huinink JA, Brandt KH. Familial benign recurrent intrahepatic cholestasis: Interrelation with intrahepatic cholestasis of pregnancy and from oral contraceptives. Gastroenterology 1976;71:202-7.

31. Jacquemin E, Cresteil D, Manouvrier S, Boute O, Hadchouel M. Heterozygous non-sense mutation of the MDR3 gene in familial intrahepatic cholestasis of pregnancy. Lancet 1999;353:210-1.

32. Jansen PLM, Peters WHM, Lamers WH. Hereditary chronic conjugated hyperbilirubinemia in mutant rats caused by defective hepatic anion transport. Hepatology 1985;5:573-9.

33. Oude Elferink RP, de Haan J, Lambert KJ, Hagey LR, Hofmann AF, Jansen PL. Selective hepatobiliary transport of nordeoxycholate side chain conjugates in mutant rats with a canalicular transport defect. Hepatology 1989;9:861-5.

34. Kitamura T, Alroy J, Gatmaitan Z, et al. Defective biliary excretion of epinephrine metabolites in mutant $\left(\mathrm{TR}^{-}\right)$rats: Relation to the pathogenesis of black liver in the Dubin-Johnson-syndrome and Correidale sheep with an analogous excretory defect. Hepatology 1992;15:1154-9.

35. Büchler M, König J, Brom M, et al. cDNA cloning of the hepatocyte canalicular isoform of the multidrug resistance protein, cMrp reveals a novel conjugate export pump deficient in hyperbilirubinemic mutant rats. J Biol Chem 1996;271:15091-8.

36. Paulusma CC, Bosma PJ, Zaman GJR, et al. Congenital jaundice in rats with a mutation in a multidrug resistance associated protein gene. Science 1996;271:1126-8.

37. Paulusma CC, Kool M, Bosma PJ, et al. A mutation in the human canalicular multispecific organic anion transporter gene causes the Dubin-Johnson syndrome. Hepatology 1997;25:1539-42.

38. Kajihara S, Hisatomi A, Mizuta T, et al. A splice mutation in the human canalicular multispecific organic anion transporter gene causes Dubin-Johnson syndrome. Biochem Biophys Res Commun 1998;253:454-7.

39. Kartenbeck J, Leuschner U, Mayer R, Keppler D. Absence of the canalicular isoform of the NW gene-encoded conjugate export pump from the hepatocytes in Dubin-Johnson syndrome. Hepatology 1996;23:1061-6.

40. Cohen L, Lewis C, Arias IM. Pregnancy, oral contraceptives, and chronic familial jaundice with predominantly conjugated hyperbilirubinemia (Dubin-Johnson syndrome) Gastroenterology 1972;62:1182-90.

41. Setchel KDR, Street JM. Inborn errors of bile acid synthesis. Semin Liver Dis 1987;7:85-99.

42. Clayton PT. Inborn errors of bile acid metabolism. J Inher Metab Dis 1991;14:478-96.

43. Stieger B, Zhang J, O’Neill B, Sjovall J, Meier PJ. Differential interaction of bile acids from patients with inborn errors of bile acid synthesis with hepatocellular bile acid transporters. Eur J Biochem 1997;244:39-44.

44. Arnon R, Yoshimura T, Reiss A, Budal K, Lefkowitch JH, Javitt NB. Cholesterol 7-hydroxylase knockout mouse: a model for monohydroxy bile acid-related neonatal cholestasis. Gastroenterology 1998;115:1223-8.

45. Setchell KD, Schwarz M, O'Connell NC, et al. Identification of a new inborn error in bile acid synthesis. Mutation of the oxysterol 7alpha-hydroxylase gene causes severe neonatal liver disease. J Clin Invest 1998;102:1690-703.

46. de Vree JML, Ottenhoff R, Smith AJ, Aten J, Grown AK, Oude Elferink RPJ. Rapid correction of mdr2 deficiency by transportation of MDR3 transgenic hepatocytes. Hepatology 1998;28:387A (Abst) 


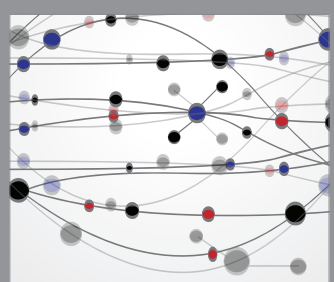

The Scientific World Journal
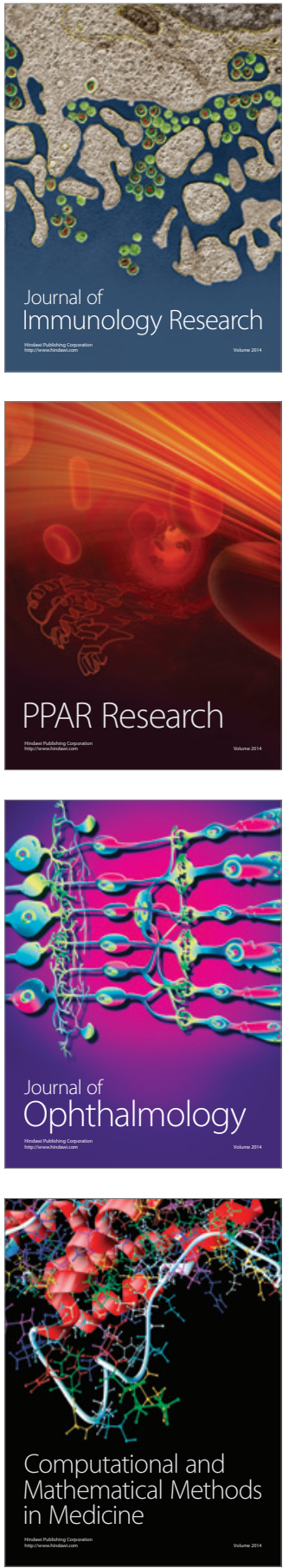

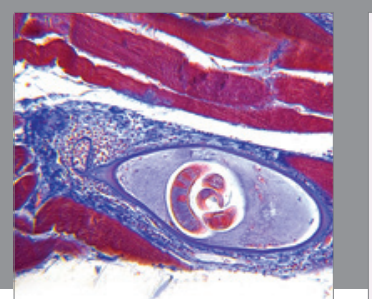

Gastroenterology Research and Practice

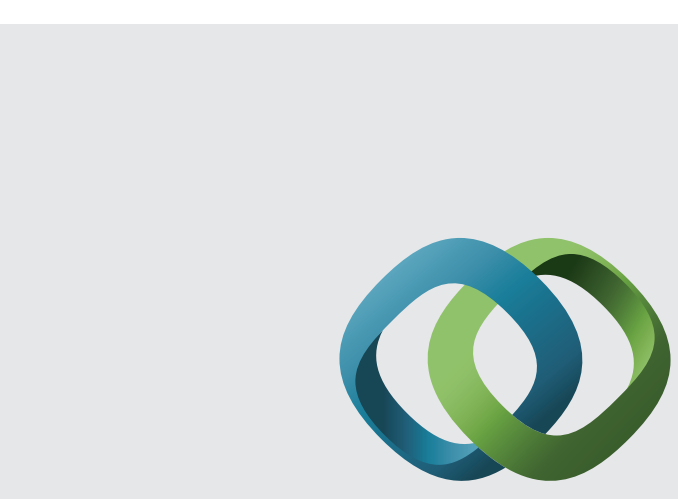

\section{Hindawi}

Submit your manuscripts at

http://www.hindawi.com
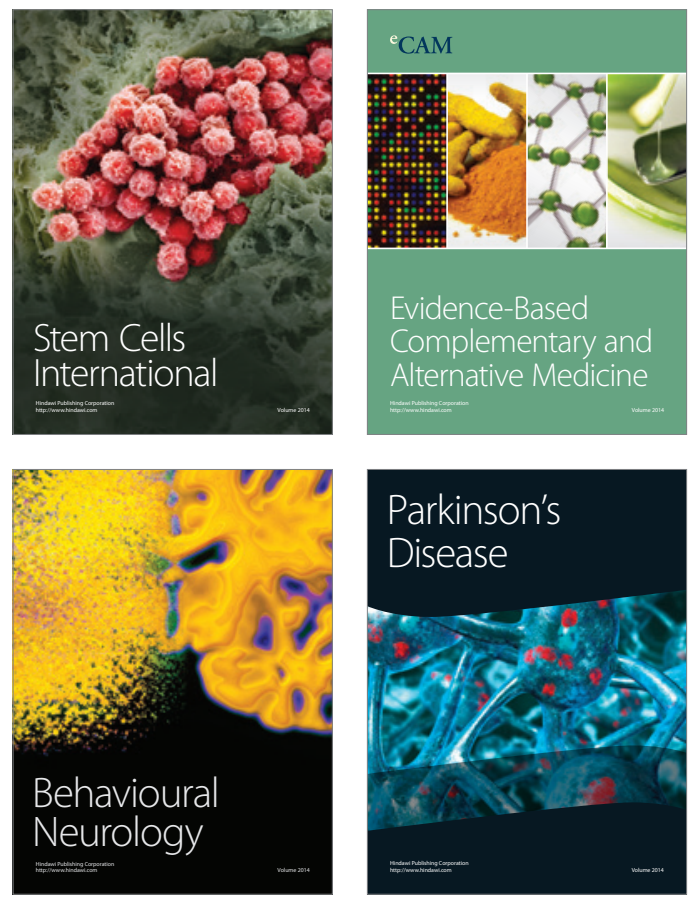
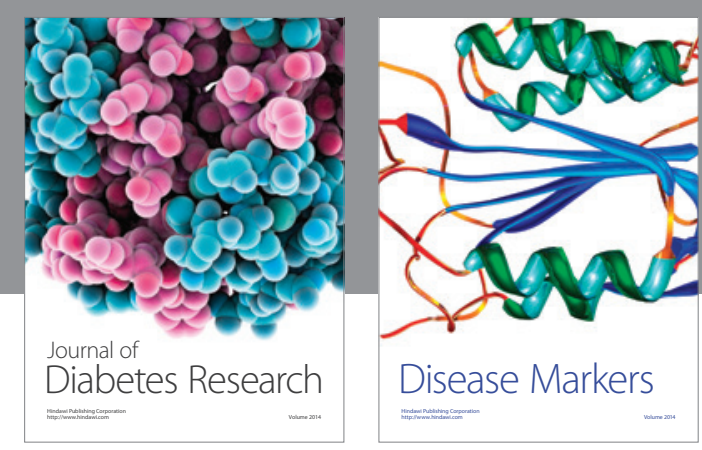

Disease Markers
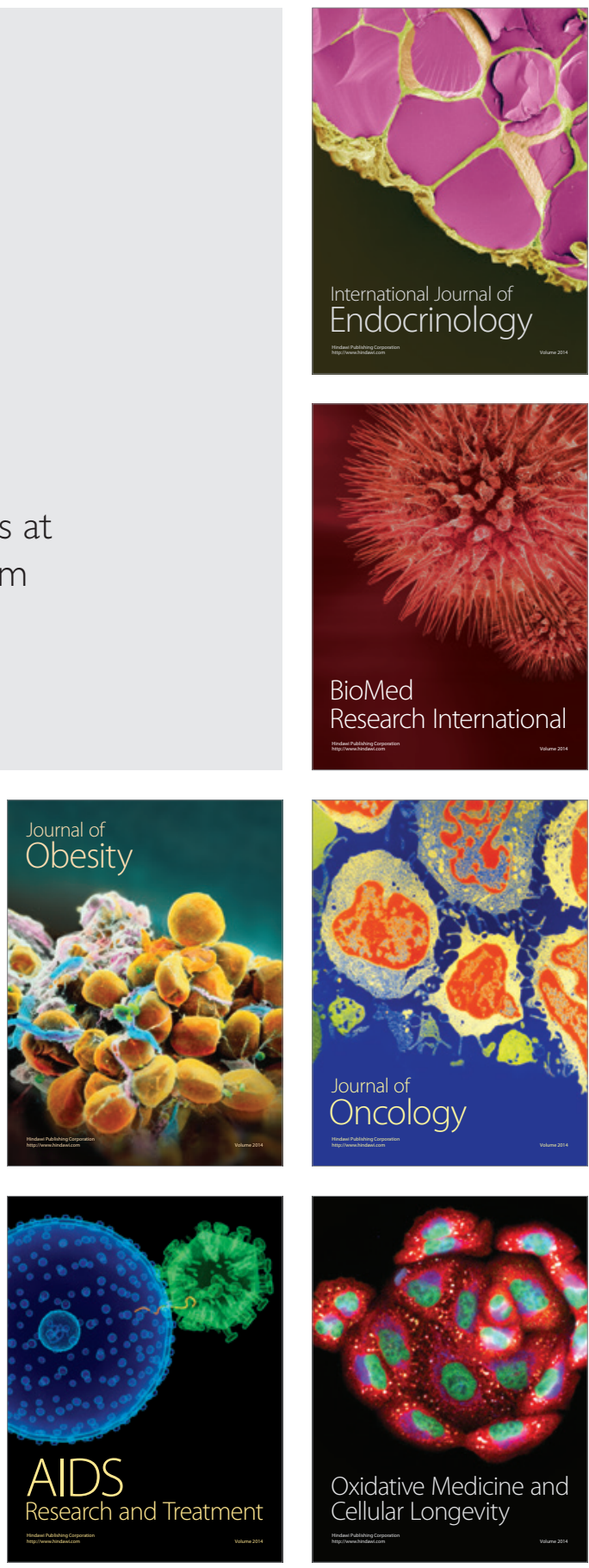